\title{
BMJ Open Compliance with current VTE prophylaxis guidelines and risk factors linked to complications of VTE prophylaxis in medical inpatients: a prospective cohort study in a Spanish internal medicine department
}

\author{
Ignacio Novo-Veleiro, ${ }^{1}$ Lucía Alvela-Suárez, ${ }^{2}$ Alba Costa-Grille, ${ }^{3}$ \\ Javier Suárez-Dono, ${ }^{1}$ Fernando Ferrón-Vidan, ${ }^{1}$ Antonio Pose-Reino ${ }^{1}$
}

To cite: Novo-Veleiro I, AlvelaSuárez L, Costa-Grille A, et al. Compliance with current VTE prophylaxis guidelines and risk factors linked to complications of VTE prophylaxis in medical inpatients: a prospective cohort study in a Spanish internal medicine department. BMJ Open 2018;8:e021288. doi:10.1136/ bmjopen-2017-021288

- Prepublication history for this paper is available online. To view these files, please visit the journal online (http://dx.doi. org/10.1136/bmjopen-2017021288).

Received 19 December 2017 Revised 1 April 2018 Accepted 13 April 2018
Check for updates

${ }^{1}$ Internal Medicine Department, University Hospital of Santiago de Compostela, Santiago de Compostela, Spain

2Internal Medicine Department, HM Rosaleda Hospital, Santiago de Compostela, Spain

${ }^{3}$ Geriatrics Department, University Hospital of Getafe, Getafe, Madrid, Spain

Correspondence to Dr Ignacio Novo-Veleiro; ignacio.novo.veleiro@gmail.com

\section{ABSTRACT}

Objectives To evaluate the degree of compliance with the current guidelines regarding venous thromboembolism (VTE) prophylaxis in medical patients during admission and to identify risk factors linked to complications of VTE prophylaxis.

Design Prospective cohort study.

Setting The Internal Medicine Department of the University Hospital of Santiago de Compostela (tertiary referral hospital).

Participants A total of 396 hospitalised, elderly patients who did not undergo surgery and had no active or previous oral anticoagulation or low molecular weight heparin (LMWH) treatment (during the previous year) and who received VTE prophylaxis during admission.

Primary and secondary outcome measures The degree of compliance with the current guidelines was estimated by calculating PADOVA and IMPROVE indexes in all cases. We analysed the development of the following complications: major and minor bleeding, major and minor haematoma and decrease of platelet count.

Results We found that VTE prophylaxis was correctly indicated in $88.4 \%$ of patients. We found two $(0.5 \%)$ cases with major bleeding, 17 (4.3\%) with minor bleeding, $30(7.6 \%)$ with decreased platelet count, 29 (7.3\%) with major haematoma and $82(20.7 \%)$ with minor haematoma. After multivariate logistic regression analysis, the presence of major haematomas was linked to obesity (OR 4.1; 95\% Cl 1.8 to 9.2, $p=0.001$ ), concomitant antiplatelet treatment (OR $2.7 ; 95 \% \mathrm{Cl} 1.1$ to 6.5 , $p=0.03$ ) and enoxaparin use (OR 3.5; 95\% Cl 1.1 to 10.9 , $\mathrm{p}=0.029$ ), and the presence of minor haematomas was associated with PADOVA index $<4$ points (OR $3.1 ; 95 \% \mathrm{Cl}$ 1.5 to $6.4, \mathrm{p}=0.003$ ) and diabetes mellitus (OR 2; $95 \% \mathrm{Cl}$ 1.1 to $3.7, p=0.031$ ).

Conclusions Complications during VTE prophylaxis in elderly hospitalised medical patients are frequent even with correct application of current guidelines. The main factors linked to haematomas were obesity and concomitant antiplatelet treatment, the presence of which should lead physicians to exercise extreme caution.

\section{Strengths and limitations of this study}

- Clinical study in elderly patients, who are usually excluded from large studies.

- Analysis of compliance with current guidelines for venous thromboembolism (VTE) prophylaxis in real-world conditions.

- Detection of minor complications and risk factors that have usually been underestimated in previous studies.

- Observational study conducted in only one department of a single hospital, which did not allow for an accurate homogenisation of subgroups.

- The inclusion of patients with VTE prophylaxis only could introduce selection bias.

The use of tinzaparin for VTE prophylaxis in these patients could have a better safety profile.

\section{INTRODUCTION}

Low molecular weight heparin (LMWH) is widely prescribed in hospitalised patients who meet high-risk criteria for venous and pulmonary embolism. ${ }^{1}$ The criteria for prescribing LMWH have been redefined by the American College of Chest Physicians. They now place an emphasis on calculating the risk of venous thromboembolism (VTE) development and the bleeding risk before starting VTE prophylaxis on both surgical and non-surgical inpatients. ${ }^{2}$ In this sense, it is worth noting that the factors linked to higher bleeding risk have been intensely analysed in patients who have undergone surgical procedures, but there is a lack of data for non-surgery patients. ${ }^{4}$ Moreover, the occurrence of some non-life-threatening secondary 
effects, such as abdominal haematomas, has been poorly studied during VTE prophylaxis in patients who have not undergone surgery. ${ }^{5}$

The alignment of real daily clinical practice with the current recommendations is another interesting point that deserves attention. Previous studies showed an acceptable match between guidelines and clinical practice in surgical patients but, again, only a few observational studies in non-surgical patients have analysed this fact. $^{16-8}$

The aims of the present study were, therefore, on the one hand, to analyse compliance with current VTE prophylaxis guidelines in non-surgical patients in an internal medicine department and, on the other hand, to describe the incidence of major and minor secondary effects with LMWH prophylaxis and to detect potential risk factors linked to them.

\section{PATIENTS AND METHODS}

The inclusion criteria were hospitalised non-surgical patients with no active or previous oral anticoagulation or LMWH treatment (during the previous year). There was no restriction with regard to the cause of hospital admission. In all cases, physicians indicated VTE prophylaxis with no intervention from the study staff. Written informed consent was obtained from all patients and data collection was performed through a personal interview by trained staff and a review of their electronic medical history.

Age-adjusted Charlson's index (ACI) was used to assess the comorbidity degree of the patients included. ${ }^{9}$ We also applied the Barthel's index (BI) to calculate functional status ${ }^{10}{ }^{10}$ the CONUT Score (CS) to detect and establish nutritional deficiencies ${ }^{11}$ and the Pfeiffer's test $(\mathrm{PT})$ to conduct a mental status evaluation of all the patients included. ${ }^{12}$

In light of current recommendations, the PADOVA index was calculated in all cases to check the adherence of the clinical practice to guidelines. ${ }^{4}$ VTE prophylaxis was considered as indicated with at least four points in PADOVA index. ${ }^{13}$ The IMPROVE index was used to calculate bleeding risk, with patients with at least seven points considered as high-risk patients. ${ }^{14}$

Chronic kidney disease (CKD) was assessed in patients with decreased glomerular filtration rate (GFR) $(<60 \mathrm{~mL} /$ $\min$ ) for at least 3 months before admission, following the current guidelines. ${ }^{15}$ Acute kidney injury (AKI) was considered in patients with GFR $<60 \mathrm{~mL} / \mathrm{min}$ at admission without previous diagnosis of CKD. Patients with previous CKD and worsening of GFR at admission were coded as CKD exacerbation (CKDE). GFR was calculated using the 2009 CKD-Epidemiology Collaboration (EPI) creatinine equation in all cases. ${ }^{16}$

All patients with a body mass index (BMI) over $30 \mathrm{~kg} / \mathrm{m}^{2}$ were considered obese. For the main alterations in blood count, we applied WHO criteria for anaemia and we classified all patients with values under $120000 / \mu \mathrm{L}$ at admission as having thrombocytopenia. We considered as elevated all cases of coagulation test with an international normalised ratio (INR) over 1.2 or activated partial thromboplastin time (APTT) over $35 \mathrm{~s}$.

The heparin types available in our centre for the duration of the study were only enoxaparin and tinzaparin, which are therefore the only heparins included in our analysis.

With regard to the analysed complications, we defined them as follows.

- Major bleeding: gastrointestinal or intracranial bleeding, haemoptysis, epistaxis or haematuria with a decrease of at least $2 \mathrm{~g} / \mathrm{dL}$ in the haemoglobin level.

- Minor bleeding: haemoptysis, epistaxis or haematuria without changes in haemoglobin levels or with a decrease of less than $2 \mathrm{~g} / \mathrm{dL}$.

- Platelet count decrease: loss of at least $50 \%$ compared with the baseline value.

- Major haematoma: retroperitoneal or straight abdominal muscle locations were considered as major haematoma in all cases. We also considered as major haematoma an abdominal haematoma in other locations in which a loss of at least two points in haemoglobin levels was implied.

- Minor haematoma: abdominal wall haematoma (any location) with an extension of more than $5 \mathrm{~cm}$ without haemoglobin loss or with a haemoglobin loss lower than two points. We also considered as minor haematoma all abdominal wall haematomas of any extension, which caused symptoms like pain or pruritus requiring specific treatment.

- Pulmonary embolism: we coded all cases diagnosed during the hospital stay that were undiagnosed and unsuspected at admission.

- Deep venous thrombosis: we considered all cases diagnosed during the hospital stay that were undiagnosed and unsuspected at admission.

A descriptive analysis was performed by calculating qualitative-variable rates plus mean and SD. We used the $\mathrm{X}^{2}$ test or Fisher's exact test, as appropriate (expected frequency value $<5$ ), to compare qualitative variables, and the Student's t-test for quantitative variables. A multivariate logistic regression analysis was conducted to identify factors associated with complications. A $\mathrm{p}$ value $<0.05$ was regarded as significant. All analyses were performed using the SPSS V.22.0 software package.

\section{Patient and public involvement}

There was no patient or public involvement in the development of the study design, protocol, recruitment or dissemination of results.

\section{RESULTS}

We included 396 consecutive inpatients who were given VTE prophylaxis during their hospital stay. Regarding gender, $51.8 \%$ were women and the global mean age was 80.7 years $(\mathrm{SD}=11.5$, range $=22-107), 91 \%$ of patients 
Table 1 Global baseline characteristics and analysis of differences regarding the type of LMWH used for VTE prophylaxis

\begin{tabular}{|c|c|c|c|c|}
\hline Variable & Global (396) & $\begin{array}{l}\text { Tinzaparin } \\
(120)\end{array}$ & $\begin{array}{l}\text { Enoxaparin } \\
\text { (276) }\end{array}$ & $P$ values \\
\hline Male & $191(48)$ & $57(47.5)$ & $134(48.5)$ & 0.848 \\
\hline Age & $80.7(11.6)$ & $83(9.6)$ & $79.8(12.2)$ & 0.083 \\
\hline CKD & $91(23)$ & $43(36)$ & $48(17)$ & $<0.001$ \\
\hline $\begin{array}{l}\text { Diabetes } \\
\text { mellitus }\end{array}$ & $112(28)$ & $38(32)$ & $74(27)$ & 0.324 \\
\hline Neoplasia & $37(9)$ & $11(9)$ & $26(9)$ & 0.928 \\
\hline Obesity & $113(28.5)$ & $30(25)$ & $83(30)$ & 0.342 \\
\hline Previous VTE & $4(1)$ & $3(2.5)$ & $1(0.4)$ & 0.085 \\
\hline 30-day surgery & $5(1)$ & $1(1)$ & $4(1.5)$ & 0.521 \\
\hline Stroke & $49(12)$ & $13(11)$ & $36(13)$ & 0.539 \\
\hline $\begin{array}{l}\text { Autoimmune } \\
\text { disease }\end{array}$ & $17(4)$ & $2(2)$ & 15 (5.5) & 0.089 \\
\hline Liver disease & $24(6)$ & $8(7)$ & $16(5.5)$ & 0.739 \\
\hline $\begin{array}{l}\text { Antiplatelet } \\
\text { treatment }\end{array}$ & $182(46)$ & $53(44)$ & $129(47)$ & 0.271 \\
\hline $\begin{array}{l}\text { Infectious } \\
\text { disease }\end{array}$ & $316(80)$ & $92(77)$ & $224(81)$ & 0.306 \\
\hline Anaemia & 156 (39) & $54(45)$ & $102(37)$ & 0.116 \\
\hline AKI & $95(24)$ & $41(34)$ & 54 (19.5) & 0.002 \\
\hline $\begin{array}{l}\text { CKD } \\
\text { exacerbation }\end{array}$ & $79(20)$ & 39 (32.5) & $40(14.5)$ & $<0.001$ \\
\hline Heart failure & $137(34.5)$ & $50(42)$ & 87 (31.5) & 0.051 \\
\hline PADOVA >4 & $342(86)$ & $112(93)$ & $230(83)$ & 0.001 \\
\hline IMPROVE >7 & $24(6)$ & $9(7.5)$ & $15(5.5)$ & 0.387 \\
\hline BARTHEL $<20$ & $56(14)$ & $21(17.5)$ & 35 (13) & 0.218 \\
\hline PFEIFFER $>5$ & 154 (39) & $51(42.5)$ & 103 (37) & 0.257 \\
\hline
\end{tabular}

Data are showed as $\mathrm{n}(\%)$ or mean (SD).

AKI, acute kidney injury; CKD, chronic kidney disease;

$\mathrm{LMWH}$, low molecular weight heparin; VTE, venous

thromboembolism. PADOVA $>4$, high risk for VTE; IMPROVE $>7$,

high bleeding risk; BARTHEL $<20$, high functional limitation;

PFEIFFER $>5$, established cognitive impairment.

were aged over 65 years. Only 32 patients $(8.1 \%)$ lived in nursing homes and the average scores of the different classification tools applied at admission were ACI 5.5 $(\mathrm{SD}=2.2)$ points, $\mathrm{BI} 55.5(\mathrm{SD}=35.5)$ points, PT $3.3(\mathrm{SD}=3)$ mistakes and CS $6.2(\mathrm{SD}=2.6)$ points. $\mathrm{CKD}$ was present in $91(23.2 \%)$ patients and diabetes mellitus in 111 (28.3\%), as well as obesity in 111 patients $(28.3 \%)$. Other remarkable comorbidities were active cancer (37 patients, $9.5 \%$ ) and haematological diseases (nine patients, 2.5\%) The complete baseline characteristics and frequencies of the main thrombosis risk factors are detailed in table 1.

After the application of the PADOVA index, we found that VTE prophylaxis was correctly indicated in $88.4 \%$ of patients following these criteria, which means that VTE prophylaxis was prescribed in 46 low-risk patients. In the case of the IMPROVE index, we found that $6.3 \%$ of patients had a high theoretical bleeding risk, which should advise against VTE prophylaxis prescription. There were 22 patients $(5.7 \%)$ who fulfilled both PADOVA and IMPROVE criteria, which means concomitant high risk of VTE and bleeding. We only found two patients $(0.5 \%)$ with fewer than four points in the PADOVA index and high bleeding risk in the IMPROVE index.

Regarding their general condition at admission, $316(79.8 \%)$ patients presented with an infection, 155 (39.1\%) had anaemia, $137(34.6 \%)$ had an acute heart failure, 95 (24\%) met AKI criteria and 79 (19.9) met CKDE criteria. In platelet count and coagulation tests, 93 (23.5\%) patients had elevated coagulation tests at admission and 27 (6.8\%) had thrombocytopenia.

With regard to VTE prophylaxis, the most used LMWH was enoxaparin (69.7\% of cases) followed by tinzaparin $(30.3 \%)$ and the mean duration was $12(\mathrm{SD}=11.8)$ days. The most commonly used treatment regimens were 4000 IU daily for enoxaparin (219 patients) and 3500 IU daily for tinzaparin (103 patients). The dose adjustment in patients with CKD, CKDE or AKI was correct in all cases. We did not register any episode of VTE during the study period.

With regard to complications, we found two patients $(0.5 \%)$ who presented with major bleeding, 17 (4.3\%) with a minor bleeding episode, $30(7.6 \%)$ developed a platelet count decrease, $29(7.3 \%)$ had a major haematoma (nine located in straight abdominal muscles and 20 in other abdominal locations) and $82(20.7 \%)$ had a minor haematoma. All patients who developed complications were managed through conservative treatment and the course was favourable in all cases. After the univariate analysis, we found an association between minor bleeding and the presence of anaemia at admission and AKI. In the case of major haematomas, this analysis showed significant differences in patients with obesity, concomitant antiplatelet treatment, an infection or heart failure as main cause of admission and the use of enoxaparin. With regard to minor haematomas, we found an association with diabetes and a PADOVA index lower than four points. Finally, a platelet count decrease was only linked to an infection as the cause of admission and it was not associated with the other analysed complications.

After multivariable analysis, none of the variables showed an association with minor bleeding or platelet count decrease. The presence of major haematomas was linked to obesity (OR 4.1; 95\% CI 1.8 to $9.2, \mathrm{p}=0.001$ ), concomitant antiplatelet treatment (OR 2.7; 95\% CI 1.1 to $6.5, \mathrm{p}=0.03)$ and enoxaparin use (OR $3.5 ; 95 \%$ CI 1.1 to $10.9, \mathrm{p}=0.029$ ), and the presence of minor haematomas was associated with the absence of indication of VTE prophylaxis following recommendations (PADOVA index $<4$ points) (OR 3.1; 95\% CI 1.5 to $6.4, \mathrm{p}=0.003$ ) and the presence of diabetes mellitus (OR 2; 95\% CI 1.1 to $3.7, \mathrm{p}=0.031$ ).

In view of these results, we performed a subanalysis to compare the clinical profile of patients who received enoxaparin and tinzaparin, which showed significant differences regarding renal function only, as shown in table 1. 


\section{DISCUSSION}

The present study shows, for the first time to our knowledge, an exhaustive analysis of clinically relevant complications and their main risk factors during VTE prophylaxis in non-surgical patients.

The high degree of observed compliance with the current guidelines in clinical practice is remarkable. There is, however, a narrow margin for improvement, particularly in the case of overprescription in low-risk patients. Our study included only patients given VTE prophylaxis during hospital stay, which makes comparison with studies such as ENDORSE (Evaluation of Patients at Risk of Venous Thrombosis in the Acute Hospital Care-Setting) or AVAIL ME difficult because they showed lower percentages of correct application of recommendations, even as low as below $50 \%$. ${ }^{17} 18$

Another relevant difference of our study is that it is exclusively confined to medical patients, as well as the extremely high age and degree of comorbidity of our cohort, compared with larger series in which patients with a mean age more than 10 years younger and very low rates of multiple comorbidity were included. ${ }^{19} 20$

The absence of VTE cases in our study reflects a high efficacy of VTE prophylaxis in medical patients, which has been studied extensively and supported by high-quality evidence. ${ }^{21} 22$

With respect to complications, we analysed minor complications such as haematomas that are usually undervalued by physicians but are important for patients. Indeed, we consider that our results could help physicians to improve their daily clinical practice and the patient's experience during a hospital admission by adding tools to detect patients at risk of developing these complications.

Bleeding episodes were infrequent, but the association between anaemia and minor bleeding could reflect the existence of previous digestive tract bleeding, increased during admission by LMWH. The association with AKI could be explained by a heparin overeffect in these patients, although we did not detect significant rates of unadjusted dosage in our cohort. In fact, an increased bleeding risk was one of the main risk factors considered on the IMPROVE score, although anaemia was not a useful marker of bleeding risk in that study. ${ }^{14}$ Thus, our results could contribute to expanding the tools available to identify patients with high bleeding risk before prescribing VTE prophylaxis.

In the case of major haematomas, we must underscore the relatively high percentage of patients who developed these complications. Despite the clinical relevance of abdominal and retroperitoneal haematomas, these complications were not analysed in any cohort study, and thus we can only compare our results with case reports. ${ }^{142324}$ In this sense, previous reports suggested an estimated incidence of $5 \%$ for abdominal haematomas in patients receiving VTE prophylaxis, which could be comparable to our results. ${ }^{25}$ With regard to risk factors, previous studies showed that elderly patients had a higher risk of abdominal haematomas ${ }^{2325} 26$; we did detect such an association, probably because of the small number of patients aged less than 65 years. Concomitant antiplatelet treatment has been identified as a risk factor linked to haematomas by other authors because of its synergic action with $\mathrm{LMWH}$, and our findings reinforce the importance of assessing the need to maintain these drugs during hospital admission in elderly patients. ${ }^{232526}$ Obesity has also been described as a risk factor in previous studies, ${ }^{25} 27$ and this relationship could be due to an adipose tissue dysfunction in obese patients, linked to an abnormal subcutaneous vascularisation and extracellular matrix changes. ${ }^{28-30}$ These alterations lead to a higher risk of local haematomas in obese patients under VTE prophylaxis, independently of the plasmatic levels of LMWH achieved. $^{26}$

As to the different types of LMWH used in our study, we found a lower risk of major haematomas with tinzaparin as the only significant difference. Interestingly, the characteristics of patients treated with both LWMHs were different with regard to renal function, so the use of tinzaparin in patients with poorer renal function could have alerted physicians to the need for better dose adjustment. Thus, this could be considered as a potential selection bias that should be taken into account in the interpretation of our results. Despite this, a potential superior safety profile in elderly patients with high comorbidity emerges and even differences in device, needles and mode of administration should be considered. Further studies will be necessary to properly establish this difference.

With regard to minor haematomas, it is remarkable that this complication is not usually considered clinically relevant. However, we decided to include it because we considered it to be highly relevant for our patients. The association with a PADOVA index lower than four points cannot be considered as a risk factor itself, but it helps us to highlight the importance of correct application of VTE prophylaxis guidelines. Diabetes mellitus has not been previously described as a risk factor for abdominal haematoma development but microvascular diabetic complications might underlie this association. ${ }^{25}$

Despite the high percentage of patients with variations in coagulation tests $(23.5 \%)$, we found no association between these variations and the related complications. This could be due to the little relevance of most variations in coagulation tests, consisting of small increments of INR or APTT.

In light of our results, we think that the presence of any risk factor for the development of major or minor complications linked to VTE prophylaxis should lead physicians to careful consideration of the indication, dosage and time of treatment before VTE prophylaxis is prescribed, particularly in elderly patients.

\section{CONCLUSIONS}

The incidence of complications developing during VTE prophylaxis in elderly hospitalised medical patients is higher than that expected in other populations even 
when the current guidelines are correctly applied. The main factors linked to haematomas in our cohort were obesity and concomitant antiplatelet treatment, the presence of which should lead physicians to exercise extreme caution. The use of tinzaparin for VTE prophylaxis in these patients could have a better safety profile.

Contributors IN-V, LA-S and AP-R contributed to study concept, design and preparation of manuscript. IN-V, LA-S and AC-G contributed to the acquisition of subjects and/or data. IN-V, JS-D, FF-V and AP-R were involved in the analysis and interpretation of data.

Funding The authors have not declared a specific grant for this research from any funding agency in the public, commercial or not-for-profit sectors.

Competing interests None declared.

Patient consent Not required.

Ethics approval Clinical Investigations Ethics Committee of Galicia.

Provenance and peer review Not commissioned; externally peer reviewed.

Data sharing statement Technical appendix, statistical code, and dataset will be available from the Dryad repository if required.

Open Access This is an Open Access article distributed in accordance with the Creative Commons Attribution Non Commercial (CC BY-NC 4.0) license, which permits others to distribute, remix, adapt, build upon this work non-commercially, and license their derivative works on different terms, provided the original work is properly cited and the use is non-commercial. See: http://creativecommons.org/ licenses/by-nc/4.0/

(C) Article author(s) (or their employer(s) unless otherwise stated in the text of the article) 2018. All rights reserved. No commercial use is permitted unless otherwise expressly granted.

\section{REFERENCES}

1. Nieto Rodríguez JA. ENDORSE. [Venous thromboembolism risk and antithrombotic prophylaxis among patients admitted to Spanish hospitals (ENDORSE study)]. Med Clin 2009;133:1-7.

2. Gould MK, Garcia DA, Wren SM, et al. Prevention of VTE in nonorthopedic surgical patients: antithrombotic therapy and prevention of thrombosis, 9th ed: American College of Chest Physicians evidence-based clinical practice guidelines. Chest 2012;141:e227

3. Falck-Ytter Y, Francis CW, Johanson NA, et al. Prevention of VTE in orthopedic surgery patients: antithrombotic therapy and prevention of thrombosis, 9th ed: American College of Chest Physicians evidence-based clinical practice guidelines. Chest 2012;141:e278.

4. Kahn SR, Lim W, Dunn AS, et al. Prevention of VTE in nonsurgical patients: antithrombotic therapy and prevention of thrombosis, 9th ed: American College of Chest Physicians evidence-based clinical practice guidelines. Chest 2012;141:e195.

5. Decousus H, Tapson VF, Bergmann JF, et al. Factors at admission associated with bleeding risk in medical patients: findings from the IMPROVE investigators. Chest 2011;139:69-79.

6. Ruiz-Artacho P, Pérez Peña C, Iriarte A, et al. [Adequation of thromboprophylaxis during former admission in patients attended in emergencies with thromboembolic disease]. Med Clin 2013;141:130-1.

7. Gallardo Jiménez P, Guijarro Merino R, Vallejo Herrera V, et al. [Assessment of venous thromboembolism risk in hospitalized medical patients. Concordance between PRETEMED guide and the recommendations of the viii conference of the American College of Chest Physicians]. Med Clin 2012;139:467-72.

8. Borobia AM, Fernández Capitán C, Iniesta Arandia N, et al. [Risk of thromboembolic events and evaluation of the use of venous thromboembolism prophylaxis in hospitalized medical patients and after discharge]. Rev Clin Esp 2009;209:15-20.

9. Charlson ME, Pompei P, Ales KL, et al. A new method of classifying prognostic comorbidity in longitudinal studies: development and validation. J Chronic Dis 1987;40:373-83.

10. Mahoney FI, Barthel DW. Functional evaluation: the barthel index. Md State Med J 1965;14:61-5.

11. Ignacio de Ulíbarri J, González-Madroño A, de Villar NG, et al. CONUT: a tool for controlling nutritional status. First validation in a hospital population. Nutr Hosp 2005;20:38-45.

12. Pfeiffer E. A short portable mental status questionnaire for the assessment of organic brain deficit in elderly patients. J Am Geriatr Soc 1975;23:433-41.

13. Barbar S, Noventa F, Rossetto $\mathrm{V}$, et al. A risk assessment model for the identification of hospitalized medical patients at risk for venous thromboembolism: the Padua Prediction Score. J Thromb Haemost 2010;8:2450-7.

14. Hostler DC, Marx ES, Moores LK, et al. Validation of the International Medical Prevention Registry on venous thromboembolism bleeding risk score. Chest 2016;149:372-9.

15. National Guideline Clearinghouse (NGC). Guideline summary: KDIGO 2012 clinical practice guideline for the evaluation and management of chronic kidney disease. In. National Guideline Clearinghouse (NGC) [Web site. Rockville (MD): Agency for Healthcare Research and Quality (AHRQ), 2013. https://www.guideline.gov (cited 2017 Jun 29).

16. Levey AS, Stevens $L A$, Schmid $C H$, et al. A new equation to estimate glomerular filtration rate. Ann Intern Med 2009;150:604-12.

17. Taher AT, Aoun J, Salameh P. The AVAIL ME study: a multinational survey of VTE risk and prophylaxis. J Thromb Thrombolysis 2011;31:47-56

18. Cohen AT, Tapson VF, Bergmann J-F, et al. Venous thromboembolism risk and prophylaxis in the acute hospital care setting (ENDORSE study): a multinational cross-sectional study. The Lancet 2008;371:387-94.

19. Nieto JA, Cámara T, Camacho I, et al. Venous thromboembolism prophylaxis in acutely ill hospitalized medical patients. A retrospective multicenter study. Eur J Intern Med 2014;25:717-23.

20. Tapson VF, Decousus H, Pini M, et al. Venous thromboembolism prophylaxis in acutely ill hospitalized medical patients: findings from the International Medical Prevention Registry on Venous Thromboembolism. Chest 2007;132:936-45.

21. Francis CW. Clinical practice. Prophylaxis for thromboembolism in hospitalized medical patients. N Engl J Med 2007;356:1438-44.

22. Dentali F, Douketis JD, Gianni M, et al. Meta-analysis: anticoagulant prophylaxis to prevent symptomatic venous thromboembolism in hospitalized medical patients. Ann Intern Med 2007;146:278-88.

23. Triscott J, Mercer S, Tian PG, et al. Retroperitoneal haematoma associated with enoxaparin use in an elderly woman with chronic kidney disease. BMJ Case Rep 2015;2015:bcr2015211699.

24. Madridano O, Martín Del Pozo M, Masso P, et al. [Hematoma of the rectus abdominis muscle in patients treated with low-molecularweight heparin: four clinical cases]. Rev Clin Esp 2011;211:109-10.

25. Nourbakhsh E, Anvari R, Nugent K. Abdominal wall hematomas associated with low-molecular-weight heparins: an important complication in older adults. J Am Geriatr Soc 2011:59:1543-5.

26. Macías-Robles MD, Peliz MG, Gonzalez-Ordonez AJ. Prophylaxis with enoxaparin can produce a giant abdominal wall haematoma when associated with low doses of aspirin among elderly patients suffering cough attacks. Blood Coagul Fibrinolysis 2005;16:217-9.

27. Goldstein JM, Sebire D. Abdominal wall haematoma in the obese: a dangerous phenomenon. J Surg Case Rep 2013;2013:rjt060.

28. Blüher M. Adipose tissue dysfunction in obesity. Exp Clin Endocrinol Diabetes 2009;117:241-50.

29. Baptista LS, da Silva KR, da Pedrosa CS, et al. Adipose tissue of control and ex-obese patients exhibit differences in blood vessel content and resident mesenchymal stem cell population. Obes Surg 2009;19:1304-12.

30. Spencer M, Unal R, Zhu B, et al. Adipose tissue extracellular matrix and vascular abnormalities in obesity and insulin resistance. $J$ Clin Endocrinol Metab 2011;96:E1990-E1998. 